\title{
Outsourcing, unemployment and welfare policy ${ }^{\text {is }}$
}

\author{
Christian Keuschnigg a,b,c,*, Evelyn Ribi ${ }^{\text {a }}$ \\ a University of St. Gallen, IFF-HSG, Switzerland \\ b CEPR, London, UK \\ ' CESifo, Munich, Germany
}

\section{A R T I C L E I N F O}

\section{Article history:}

Received 7 December 2007

Received in revised form 24 October 2008

Accepted 4 February 2009

\section{Keywords:}

Outsourcing

Unemployment

Social insurance

Redistribution

JEL classification:

F23

$\mathrm{H} 21$

J64

J65

L23

\begin{abstract}
A B S T R A C T
The paper investigates the consequences of outsourcing of labor intensive activities to low-wage economies. This trend challenges the two basic functions of the welfare state, redistribution and social insurance when private unemployment insurance markets are missing. The main results are: (i) outsourcing raises unemployment and labor income risk of unskilled workers; (ii) it increases inequality between high- and low-income groups; and (iii) the gains from outsourcing can be made Pareto improving by using a redistributive linear income tax if redistribution is initially not too large. We finally derive the welfare optimal redistribution and unemployment insurance policies.
\end{abstract}

(c) 2009 Elsevier B.V. All rights reserved.

\section{Introduction}

As international integration proceeds, large firms find it increasingly easy to outsource the production of labor intensive components. This trend is especially pronounced in small European countries; in the Netherlands, Denmark, and Sweden, the value of goods outsourced abroad as a share of domestic demand was close to $50 \%$ in 2000 , and it even approached 60\% in Belgium and Austria (OECD, 2007b). An important motivation is to exploit cost advantages. Imports from lowwage countries have thus substantially increased. For instance in the UK, the share of imports from developing countries has risen from $18 \%$ to $22 \%$ of total imports in the period 1982-96 (Hijzen et al., 2005). This trends seems to have accelerated most recently. Over 1995-2004, imports from non-OECD countries have grown substantially faster

\footnotetext{
is The first author greatly appreciates the hospitality of the Oxford University Centre for Business Taxation (CBT). We are grateful for many comments during seminars at CBT and Universities of Bristol, Durham, Innsbruck, Leicester, Linz, Oxford, St. Gallen, Tilburg, at the Institute for Fiscal Studies in London and the Leverhulme Centre at Nottingham University, and at annual conferences of EEA, CESifo, Royal Economic Society and German and Swiss Economic Societies. We are particularly grateful for detailed comments by two anonymous referees and the editor, Kala Krishna.

* Corresponding author. IFF-HSG, Varnbuelstrasse 19, CH-9000 St. Gallen, Switzerland. Tel.: +41 71224 3085; fax: +41712242670.

E-mail addresses: christian.keuschnigg@unisg.ch (C. Keuschnigg), evelyn.ribi@unisg.ch (E. Ribi).
}

than imports from OECD countries in most manufacturing sectors in France, Germany, Japan, UK and the US (OECD, 2007b).

Integration undoubtedly generates substantial gains on average. The benefits and costs, however, are unevenly distributed. The cost savings from outsourcing raise profits for shareholders. But asset wealth and profit income is concentrated among top income earners. For the US, Wolff (1998) reports that more than $90 \%$ of financial wealth is held by the top $20 \%$ over the years 1983-1995. This high concentration of wealth is also found in other OECD countries (see Burniaux et al., 1998). Unskilled workers cannot benefit from higher profits since their asset ownership is insignificant. In addition, outsourcing of labor intensive components deteriorates their labor market prospects, see Feenstra and Hanson (1996) for the US, Anderton and Brenton (1999) and Hijzen, Görg, and Hine (2005) for the UK, Strauss-Kahn (2003) for France, Ekholm and Hakkala (2006) for Sweden and Falk and Wolfmayr (2008) for several EU countries. In general, outsourcing reduces demand for low-skilled workers, which translates into lower wages and higher unemployment. According to OECD (2007a), the average unemployment rate in 2005 among individuals with less than upper secondary education amounts to $12.4 \%$ in European OECD countries, whereas people with upper secondary (tertiary) education face much lower unemployment rates of $6.4 \%$ (4.0\%). Unskilled workers are clearly exposed to much greater income risk than skilled workers. In sum, globalization enhances income inequality and exacerbates the income risk of low-skilled workers. It thereby creates "more demand" for the 
basic functions of the welfare state, consisting of social insurance in the absence of private unemployment insurance, and redistribution.

However, the welfare state itself creates part of the problem. Estimates of the elasticity of reservation wages with respect to unemployment benefits range from 0.11-0.17 (Lancaster and Chesher, 1983 ) to values around 0.4 (Feldstein and Poterba, 1984; Fishe, 1982; Van den Berg, 1990). The high benefits in Europe (replacement rates are mostly $60 \%$ or more, see OECD, 2004) thus significantly inflate wages. Díaz-Mora (2008) estimates that a $1 \%$ increase in firms' domestic labor cost boosts the volume of outsourcing by $0.3 \%$, and adds to outsourcing at the extensive margin by significantly raising the probability that a firm engages in subcontracting (Díaz-Mora and Triguero-Cano, 2007). Foreign countries with lower unit labor costs attract more outsourcing (Egger and Egger, 2003). We conclude that the welfare state tends to accelerate outsourcing by raising wages.

The paper investigates the consequences of outsourcing for welfare policies in high-wage economies. The theoretical model is based on two main assumptions, inspired by the stylized facts: the risk of unemployment falls on unskilled workers while firm ownership and profit income are concentrated among top earners. We consider the insurance and redistribution functions with two policy instruments, a linear income tax redistributing from high- to low-skilled workers, and unemployment insurance. The main results are: (i) outsourcing, induced by lower transport costs, depresses wages and raises lowskilled unemployment; (ii) it raises inequality; (iii) social insurance boosts wages and leads to more outsourcing and unemployment; (iv) redistribution, in contrast, reduces gross wages and unemployment of unskilled workers. By reducing the net tax on employed unskilled workers, the linear income tax acts as a wage subsidy. It allows for higher net and lower gross wages, and thus favors domestic employment over outsourcing; (v) keeping insurance constant, it is possible to use the income tax to distribute the gains from outsourcing in a Pareto improving way if tax rates are not too high. We finally characterize welfare optimal redistribution and insurance policies.

The paper is most closely related to the literature on integration and labor market performance, using models ranging from classical labor supply with full employment (e.g. Spector, 2001; Guesnerie, 2001), to search generated unemployment (e.g. Davidson et al., 1999, 2008; Davidson and Matusz, 2006) and unemployment from fair wage constraints (e.g. Egger and Kreickemeier, 2008, 2009). This paper relies on a simple static model of search unemployment because the search framework is most commonly used in empirical labor market research (cf. Krueger and Meyer, 2002; Eckstein and van den Berg, 2007) and in the literature on optimal unemployment insurance (Chetty, 2006; Gruber; 1997; Baily, 1978, among others). Although these models differ in some predictions, they share common features that are central in our model to determine unemployment and outsourcing, such as a negative relationship between wages and unemployment (see, e.g., Egger and Kreickemeier, 2008, p. 177), the simultaneous increase in profits and unemployment in response to globalization, and the tax shifting behavior so that a higher replacement rate raises producer wages and thereby leads to more unemployment (see, e.g., Egger and Kreickemeier, 2009, p. 189 and proposition 2, and 2008, p. 129). Our paper also includes a stylized analysis of wage and employment subsidies as in Davidson, Martin and Matusz (1999) because the progressive income tax redistributes from high- to low-skilled workers and, in reducing the wage tax, makes workers keener to accept job offers instead of staying unemployed. ${ }^{1}$

Spector (2001) studied whether a non-linear income tax can make trade liberalization a Pareto-improvement. ${ }^{2}$ The key difference is that

\footnotetext{
${ }^{1}$ In using a dynamic search framework, these authors can address sectoral labor reallocation, allowing them to distinguish between employment and wage subsidies to specifically target stayers and movers.

2 We use a linear income tax. We are not aware of any paper that is able to deal with non-linear income taxation when there is unemployment and profit on top of wage income. Imposing incentive compatibility conditions in non-linear income taxation tends to restrict somewhat the possibility for redistribution.
}

we combine unemployment and, thus, discrete labor supply of unskilled with intensive supply of high-skilled workers. This links our paper to the income tax literature with discrete labor supply (Immervoll et al., 2007; Blundell, 2006; Saez, 2002, among others). Saez (2002) has shown that the relative strength of the intensive and extensive responses is important in the design of optimal tax transfer schedules. The extensive margin dominates at the low end of the income distribution and can rationalize an earned income tax credit (EITC) or a wage subsidy. Eissa and Hoynes (2006) consistently find for the US that the EITC strongly increases participation while the intensive response is insignificant for low-income earners.

Our key contribution is to introduce risk-aversion. All of the papers mentioned above assume risk-neutrality and focus on the redistributive and efficiency effects. Our paper thus complements this literature by introducing gains from insurance when private unemployment insurance is not possible. We believe that this extension is necessary to evaluate both functions of the welfare state, social insurance in addition to redistribution, and it is crucial for one of our central results: globalization raises the labor income risk of unskilled workers so that governments should expand the welfare state to provide better insurance. This is consistent with the empirical finding of Rodrik (1998) that high-income countries with a larger degree of openness and exposure to external risk have significantly larger social security and welfare spending.

In the rest of the paper, Section 2 sets up the analytical model. Section 3 derives the effects of globalization and national welfare policies. Section 4 shows how the linear income tax can possibly distribute the gains from outsourcing in a Pareto improving way, and characterizes the optimal structure of insurance and redistribution policies. Section 5 concludes. The Appendix contains some technical calculations.

\section{A simple model}

The world economy consists of a high- and low-wage country, North and South. The North is endowed with a mass 1 of unskilled and a mass $N$ of skilled agents. Firms supply a homogeneous numeraire good in two alternative sectors. Our main focus is on the innovative sector where firms combine high- and low-tech inputs to manufacture the final good. In the alternative sector, the final good can be produced with a linear technology using only skilled labor. The South is endowed with low-skilled labor only which is employed in a linear production process with a low, fixed wage.

\subsection{Households}

Agents are risk averse. Given wage $r$, skilled workers supply variable labor $H$ earning an hourly wage $(1-T) r$ net of tax. They also receive profits $\bar{\pi}=\Pi / N$ per capita where $\Pi$ is aggregate profits. Assuming linearly separable preferences, welfare $V_{H}$ (index $H$ for high-skilled) is a concave increasing function of income $c_{H}$ minus effort costs $\varphi(H)$,

$V_{H}=\max _{H} u\left(c_{H}-\varphi(H)\right), \quad$ s.t. $\quad c_{H}=(1-T) r H+\bar{\pi}$.

Given convex increasing effort costs, skilled labor supply increases with the net wage, $(1-T) r=\varphi^{\prime}(H)$. Income effects are excluded.

Unskilled workers supply one unit of labor at a gross wage $w$, if employed. The ex ante probability of being unemployed $1-e$ is equal to the ex post unemployment rate. Expected utility is

$V_{L}=e \cdot u(w-\tau)+(1-e) \cdot u(b+z)$.

To protect income, the welfare state pays a benefit $b$ in the event of unemployment which adds to the money equivalent value $z$ of leisure or home production (see Blanchard and Tirole, 2008). Benefits are financed 
by contributions and are possibly cross-subsidized by skilled workers. The total tax per capita is $\tau$, reflecting the net tax liability of a linear income tax plus the contribution to the unemployment insurance (UI) scheme.

\subsection{Firms}

\subsubsection{Technology}

A high-skilled agent can either produce one unit of the high-tech input, or $r$ units of the final good in the alternative sector. Being fully mobile across sectors, she must be paid a fixed wage $r$. A low-skilled worker can only produce one unit of the low-tech input without any other option. Both inputs are combined in the innovative sector to assemble the final output good. We make three important assumptions with respect to the innovative technology. First, production is decreasing returns to scale, due to the presence of a fixed factor, reflecting unique know-how or a limited span of managerial control as in Lucas (1978). We assume that there is a mass one of innovative firms and that each one makes strictly positive profits $\pi$, reflecting the returns to the fixed factor.

Second, we assume that the innovative technology is stochastic and requires a fixed investment $f$. Given type $q^{\prime} \in[0,1]$, investment succeeds with probability $q^{\prime}$, yielding profit $\pi$. With probability $1-q^{\prime}$, the firm fails and is closed down. The cumulative distribution of firms is $G(q)=$ $\int_{0}^{q} g\left(q^{\prime}\right) d q^{\prime}$. Firm heterogeneity in success probabilities replaces the variation in factor productivity in the literature inspired by Melitz (2003). ${ }^{3}$ In our model, all firms are symmetric within each group (integrated versus outsourcing firms) which is a major simplification compared to Melitz-style heterogeneous firm models. ${ }^{4}$

Third, innovative firms choose an organizational form. An integrated firm produces low- and high-tech inputs in-house, earning profits $\pi$. Alternatively, production of low-tech inputs is outsourced to independent suppliers in the South. Despite transport costs of shipping inputs back home, we assume the wage advantage of the South to be so large that outsourcing is a cost reducing strategy and yields higher profits than integration, $\pi^{0}>\pi$. However, the parent firm must first find a suitable, independent subcontractor, transfer the technological specifications of the required input and possibly assist in preparing production. Hence, outsourcing requires a higher fixed $\operatorname{cost} f^{o}>f=0$, where the integration cost is normalized to zero for simplicity. The net expected value of a type $q^{\prime}$ firm is $\pi^{o} q^{\prime}-f^{o}$ with outsourcing and $\pi q^{\prime}$ with integration. Once the fixed cost investment is successfully completed, firms are fully symmetric within each group, earning profits of either $\pi^{0}$ or $\pi$. In the following, a firm specific variable without an index refers to integrated firms, an upper index $o$ refers to outsourcing firms.

The sequence of events is: (i) a mass one of firms is started, each drawing a success probability $q^{\prime} ;^{5}$ (ii) firms choose organizational form and invest the fixed cost; (iii) a firm succeeds with probability $q^{\prime}$. With probability $1-q^{\prime}$, the firm fails and closes down; (iv) if successful, firms start production. The model is solved backwards.

At production stage, a successful firm acquires high- and low-tech inputs, $h$ and $l$, to produce raw value added $y$ which is transformed into final output subject to decreasing returns to scale. The total technology is homothetic,

$x=F(h, l)=f(y(h, l)), \quad f(y)=A \cdot y^{\delta}, \quad y=h^{1-\alpha} l^{\alpha}, \quad 0<\alpha, \delta<1$.

\footnotetext{
${ }^{3}$ See Helpman (2006) for a review of the literature, and Grossman and Helpman (2002) and Antràs (2005) for models of outsourcing.

${ }^{4}$ See also Keuschnigg (2008). A drawback is that we cannot make statements how the changing composition of the business sector affects average factor productivity within each group of outsourcing and integrated firms. We believe that this is not crucial for the policy issues analyzed in this paper. Note, however, that even in our model production costs differ across groups.

${ }^{5}$ We do not consider endogenous entry (see Eq. (11) in Antràs and Helpman, 2004, where entry results from $R \& D$ decisions) but take the range of ideas for innovative firms as given.
}

Since $y$ is linear homogeneous, the cost per unit of value added $\omega(r, W)$ depends on prices but not on scale. The factor price $W$ not only includes the wage but also some recruitment cost, see below. Profit maximization $\pi(\omega)=\max _{y} x-\omega y$ s.t. $x=f(y)$ gives

$f^{\prime}(y)=\omega, \quad \omega(r, W)=\min _{\tilde{h}, \tilde{l}} r \tilde{h}+W \tilde{l} \quad$ s.t. $\quad \tilde{h}^{1-\alpha} \tilde{l}^{\alpha} \geq 1$.

Value added $y$ and output $x$ depend on unit factor cost. Multiplying by $y$ gives $\omega y=y f^{\prime}(y)=\delta x$ since the output elasticity $\delta$ is constant by assumption. Total profits are thus proportional to sales, $\pi=x-\omega y=$ $(1-\delta) x$. Factor demand is unit demand scaled by value added output, $h=\tilde{h} y$ and $l=\tilde{l} y$, giving total cost $\omega y=r h+W l$. The Cobb Douglas technology implies constant cost shares, $W l=\alpha \cdot \delta x$ and $r h=(1-\alpha) \cdot \delta x$.

\subsubsection{Vertical integration}

Integrated firms produce the low-tech input in-house by hiring unskilled workers on a search labor market. A firm announcing $k$ vacancies is able to hire $l=m k$ workers. Maintaining a vacancy costs $\kappa$ units of output. Once a suitably qualified worker is found, there is a job rent to be shared which is divided by Nash bargaining. For simplicity, we assume one shot matching so that no other search opportunity is available.

The firm needs $h$ units of skilled labor and $l$ units of unskilled labor. Anticipating the result of wage bargaining, it generates profits of

$\pi=\max _{h, k} x-r h-w l-\kappa k, \quad$ s.t. $\quad l=m \cdot k, \quad x=F(h, l)$.

The firm's hiring results in the following job creation and labor demand conditions,

$\left(F_{l}-w\right) \cdot m=\kappa, \quad F_{h}=r$.

The market for skilled workers is competitive. Firms hire until marginal productivity is equal to the wage. With unskilled workers, the marginal cost of investing in a job vacancy must correspond to the expected job rent. Equivalently, the total cost of an unskilled worker, $F_{l}=w+\kappa / m \equiv W$, exceeds the wage by a recruitment cost equal to the search cost times the number of vacancies needed for a successful hire.

The wage follows from bargaining over the job rent. A worker moving out of unemployment gains $w-\tau-b-z$, see Eq. (2). Given the workers' bargaining power $\gamma$, Nash bargaining $\max _{w}[u(w-\tau)-u$ $(b+z)]^{\gamma}\left[F_{l}-w\right]^{1-\gamma}$ yields

$$
(1-\gamma)[u(w-\tau)-u(b+z)]=\gamma u^{\prime}(w-\tau)\left(F_{l}-w\right) .
$$

\subsubsection{Outsourcing}

Production of low-tech inputs may be outsourced to the South where the wage rate is fixed to a low $w^{s}$. Given constant labor productivity, subcontractors must earn $w^{5}$ per unit to break even ${ }^{6}$ However, shipping back to Northern manufacturers loses $(\lambda-1) l^{s}$ in cross border transport. The subcontractor must thus produce $\lambda l^{s}, \lambda>1$, if the manufacturer needs a quantity $l^{s}$. The zero profit price for outsourced inputs is assumed to be lower than the Northern factor cost, $\lambda w^{s}<W$.

An outsourcing firm in the North employs skilled labor to produce the high-tech input in-house. Combining with low-tech imports, it assembles final output and earns a profit

$\pi^{0}=\max _{h^{o}, l^{S}} x^{0}-r h^{0}-\lambda w^{S} l^{S}, \quad$ s.t. $\quad x^{0}=F\left(h^{0}, l^{S}\right)$.

The optimal choice of inputs satisfies

$F_{h}^{o}=r, \quad F_{l}^{o}=\lambda w^{s}$

${ }^{6}$ We close the model in a separate Appendix (www.alexandria.unisg.ch/publications /41122). The South is endowed with unskilled labor, producing either final output or subcontracting. Constant labor productivity and perfect mobility imply a fixed wage. 


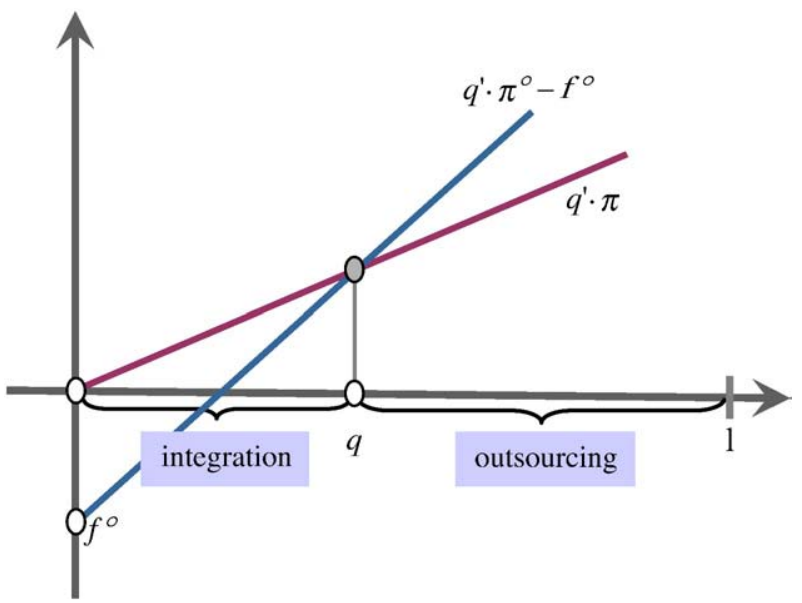

Fig. 1. Integration vs. outsourcing.

Replacing the factor price $W$ by $\lambda w^{s}$ in Eqs. (3) and (4), we obtain unit cost $\omega^{o}\left(r, \lambda w^{s}\right)$ under outsourcing, yielding value added $y^{o}$, output $x^{o}$ and profit $\pi^{o}=(1-\delta) x^{\circ}$. The Cobb Douglas technology implies constant cost shares so that $\lambda w^{S} l^{s}=\alpha \cdot \delta x^{\circ}$.

\subsubsection{Organizational choice}

Due to the cost advantage $\lambda w^{s}<W$, profits from outsourcing are larger once the fixed cost $f^{o}$ is sunk. At the beginning, a firm of type $q^{\prime}$ chooses the organizational form which yields the highest expected present value. Outsourcing is preferred if $q^{\prime} \pi^{0}-f^{0}>q^{\prime} \pi$, i.e. when the expected profit differential exceeds the fixed cost of outsourcing, $q^{\prime}\left(\pi^{0}-\right.$ $\pi)>f^{o}$. The critical firm is thus identified by

$q \cdot\left(\pi^{0}-\pi\right)=f^{0}$.

Firms with high success probabilities $q^{\prime}>q$ prefer outsourcing. Fig. 1 illustrates.

Innovative firms are independently distributed with density $g\left(q^{\prime}\right)$. The critical type in Eq. (10) determines the fraction of integrated $(s)$ and outsourcing $\left(s^{\circ}\right)$ firms,

$s=\int_{0}^{q} q^{\prime} d G\left(q^{\prime}\right), \quad s^{o}=\int_{q}^{1} q^{\prime} d G\left(q^{\prime}\right), \quad s^{f}=\int_{q}^{1} d G\left(q^{\prime}\right)$.

Of all firms, $s+s^{o}<1$ survive to production stage while $1-s-s^{o}$ fail after fixed costs are sunk. A share $s^{f}$ chooses outsourcing and invests $f^{o}$, but only a share $s^{o}<s^{f}$ actually makes it to production stage.

After success is realized, there are only two types of firms left in the innovative sector: vertically integrated and outsourcing firms. Given this symmetry, total profits are

$\Pi=s \pi+s^{o} \pi^{0}-s^{f} f^{0}$.

\subsection{Equilibrium}

The labor market for low-skilled workers and the government budget jointly determine equilibrium. ${ }^{7}$ Unskilled labor is subject to involuntary unemployment. Integrated firms post $s k$ vacancies. Given a mass 1 of job searchers, labor market tightness, i.e. the ratio of vacancies to jobseekers, is $\theta \equiv s k$. A linear homogeneous technology $e=M(1, \theta)=m \cdot \theta$ determines matching rates $e$ and $m$ which satisfy $e^{\prime}(\theta)>0>m^{\prime}(\theta)$. A tighter market increases workers' chances to get a

${ }^{7}$ The standard sector produces with a linear technology using up all remaining skilled labor. A separate Appendix (see Footnote 6) shows how trade balances and world output market equilibrium follow from Walras' Law. job but reduces chances of firms to fill vacancies. With hiring per firm equal to $l=m k$, the matching equation reflects "market clearing"

$e=s \cdot l$.

Employment is equal to aggregate labor demand which reflects employment $l$ per firm and the number $s$ of (integrated) firms actually hiring locally. Adding the government budget constraint in the North closes the model,

$T \cdot r H N+\tau \cdot e=(1-e) \cdot b$.

Equilibrium is brought about by values of an employment rate $e$ (uniquely related to market tightness $\theta$ ), and a net $\operatorname{tax} \tau$ (consisting of the income tax plus UI contribution) that simultaneously satisfy labor market clearing and fiscal budget balance.

The two policy instruments are UI benefits $b$ and the tax rate $T$ on the skilled, reflecting social insurance and redistribution policies: (i) Higher UI benefits are financed by rising contributions (as part of $\tau)$. The government thereby shifts income from the good to the bad state and provides insurance to risk averse workers. Insurance need not be actuarially fair and might be cross-subsidized by the highskilled. (ii) The government redistributes from high-wage earners to employed unskilled workers by raising the marginal tax rate $T$ to finance a tax cut or a transfer to low-income individuals. ${ }^{8}$ There is no restriction on $\tau$ being positive. A negative value corresponds to an earned income tax credit or a wage subsidy. Its main purpose is to boost labor market participation among the low-skilled by widening the income differential between work and unemployment.

\section{Globalization and welfare policy}

This section analyzes how economic equilibrium adjusts when transport costs $\lambda$ fall as a result of globalization, or when the government reconsiders its redistributive or insurance policies by changing the tax rate $T$ or benefits $b$. We derive the comparative static effects of exogenous shocks on the equilibrating values of $e(\tau ; b, \lambda)$ and $\tau(e ; b, \lambda)$ by log-linearizing the model. The hat notation denotes percentage changes relative to initial values, e.g. $\hat{e} \equiv d e / e$. Exceptions to this definition are separately indicated.

\subsection{Outsourcing and low-skilled labor}

The supply side relates the employment rate $e$ to market tightness $\theta$ which reestablishes labor market equilibrium $e=s l$ in response to economic shocks. Increased tightness raises the chances of workers to locate a job while it reduces the rate $m$ with which firms are able to fill vacancies. The matching function mentioned in Eq. (13) implies

$\hat{e}=(1-\eta) \hat{\theta}, \quad \hat{m}=-\eta \cdot \hat{\theta}, \quad \eta \equiv-\theta m^{\prime}(\theta) / m(\theta)>0$.

On the demand side, outsourcing affects the extensive and intensive margins of labor demand, $L \equiv s l$, reflecting employment per firm and the number of firms hiring at home. Log-linearizing the bargaining condition (7) in Appendix A1, leads to a wage response

$\hat{w}=\hat{\tau}+\hat{b}+\frac{1-\tau^{*}-z / w}{1+\rho \chi} \frac{\eta}{1-\eta} \hat{e}, \quad \tau^{*} \equiv \frac{\tau+b}{w}, \quad \hat{b} \equiv \frac{d b}{w}, \quad \hat{\tau} \equiv \frac{d \tau}{w}$,

where $\chi \equiv(w-\tau-b-z) /(w-\tau)$ measures the income gap between labor market states, and $\rho \equiv-c u^{\prime \prime}(c) / u^{\prime}(c)$ is the degree of relative risk aversion. Finally, $\tau^{*}$ denotes the participation tax rate and, thus, the fiscal disincentive against accepting a job offer. This distortion tends to

\footnotetext{
${ }^{8}$ The tax liability under a linear income tax is $\tau=T \cdot w-\bar{z}$.
} 
be high, easily exceeding 50\% (see Immervoll et al., 2007, for evidence in Europe), since it is the sum of benefits lost and taxes paid on the job. If measured in percent of gross wage earnings, it corresponds to the sum of the average tax rate $\tau / w$ and the replacement rate in $\mathrm{UI}, b / w$.

A higher tax on work and a more generous UI benefit raise a worker's reservation wage. Since her bargaining strength assures a strictly positive job surplus, any policy raising the reservation wage is partly shifted to firms and inflates gross wages. ${ }^{9}$ Bargaining implies that job rents of workers and firms must change in proportion. Given a wage increase, labor productivity must rise to an extent that also leaves a higher job rent to the firm. As firms expand hiring, employment and market tightness rise until the declining hiring probability satisfies again the job creation condition. In equilibrium, a higher employment rate is thus associated with a higher wage as in (16).

Labor demand per firm follows from $F_{l}=w+\kappa / m \equiv W$. Unit labor costs $W$ reflect wages plus recruitment costs $\kappa / m$ and increase by $\hat{W} \equiv \frac{w}{W} \cdot \hat{w}+\frac{\kappa / m}{W} \cdot \frac{\eta}{1-\eta} \hat{e} e$. When markets become tighter, firms need to post more vacancies per employee and incur higher recruitment costs. Substituting Eq. (16) yields the change in unit labor costs ${ }^{10}$

$\hat{W}=\frac{w}{W}\left[\psi_{e} \cdot \frac{\eta}{1-\eta} \hat{e}+\hat{\tau}+\hat{b}\right], \quad \psi_{e} \equiv \frac{1-\tau^{*}-z / w}{1+\rho \chi}+\frac{\kappa / m}{w}$.

Employment per firm depends on output and wage costs relative to the price of skilled labor. Firms rationalize on the use of unskilled labor if its relative price increases. Apart from this substitution effect, higher unskilled labor cost feeds through on total cost $\omega(r, W)$ per unit of value added. Applying the envelope theorem to (4), the percentage change is $\hat{\omega}=\alpha \hat{W}$ where $\alpha=W \tilde{l} / \omega$ is the cost share of low-tech inputs. Total costs amount to $\omega y=W l+r h$. The firm's optimal output is given by $f^{\prime}(y)=\omega$ and implies $\hat{y}=-\hat{\omega} /(1-\delta)$, which determines the supply of final goods, $\hat{x}=\delta \hat{y}$. Profits are a fixed proportion of sales, $\pi=x-\omega y=(1-\delta) x$, and thus change by

$\hat{\pi}=\hat{x}=-\frac{\alpha \delta}{1-\delta} \cdot \hat{W}, \quad \hat{l}=-\left[1+\frac{\alpha \delta}{1-\delta}\right] \cdot \hat{W}$.

Labor demand follows from cost shares being constant, $\hat{l}=\hat{\omega}+$ $\hat{y}-\hat{W}$. To sum up, a wage increase erodes profits, output and demand for unskilled labor of integrated firms.

The extensive margin of labor demand reflects the share of firms opting for outsourcing and, thus, depends on relative profits. If crossborder transport costs decline, the import price $\lambda w^{s}$ paid by Northern companies falls and outsourcing becomes cheaper. Firms outsourcing to low-wage countries save costs, their sales and profits rise. Formally, unit costs are $\omega^{o}=\omega\left(\lambda w^{s}, r^{o}\right)=\lambda w^{s} \tilde{l}^{s}+r^{0} \tilde{h}^{o}$ and rise with transport cost by $\hat{\omega}^{o}=\alpha \hat{\lambda}$. For final assembly, we have $\hat{x}^{o}=\delta \hat{y}^{\circ}$ and $\hat{\omega}^{o}=-(1-\delta) \hat{y}^{o}$ as before. Therefore,

$\hat{\pi}^{o}=\hat{x}^{0}=-\frac{\alpha \delta}{1-\delta} \cdot \hat{\lambda}$

In raising wages, welfare policy reduces profits $\pi$ of integrated firms. Outsourcing becomes relatively cheaper. In Fig. 1, the line through the origin rotates down so that a margin of firms switches to outsourcing. Labor demand shrinks in line with $s=\int_{0}^{q} q^{\prime} d G\left(q^{\prime}\right)$. Similarly, a reduction of transport costs makes outsourcing more profitable and also erodes labor demand. Log-differentiating the discrete choice in Eq. (10) yields

$\frac{\hat{q}=-\pi^{0} \hat{\pi}^{0}-\pi \hat{\pi}}{\pi^{0}-\pi=\frac{1}{\pi^{0}-\pi}\left(\lambda w^{s} l^{s} \cdot \hat{\lambda}-W l \cdot \hat{W}\right) .}$

\footnotetext{
${ }^{9}$ Tax shifting is weakened when benefits are indexed to net wages. Some tax shifting will occur as long as wage indexation of benefits is not complete.

${ }^{10}$ We adopt the convention of defining all coefficients such as $\Psi_{e}$ to be positively valued.
}

The second equality follows upon substituting profit changes and using $\pi=(1-\delta) x$ as well as $l W=\alpha \delta x$. When outsourcing expands, labor demand falls by $\mathrm{d} s=q g(q) \mathrm{d} q$ or

$\hat{s}=\mu \cdot\left(\lambda w^{s} l^{s} \cdot \hat{\lambda}-W l \cdot \hat{W}\right), \quad \mu \equiv \frac{q g(q)}{s(q)} \frac{q}{\pi^{0}-\pi}$

Aggregate labor demand changes by $\hat{L}=\hat{l}+\hat{s}$. Upon substitution,

$\hat{L}=L_{\lambda} \cdot \hat{\lambda}-L_{W} \cdot \hat{W}, \quad L_{\lambda} \equiv \mu \lambda w^{s} l^{s}, \quad L_{W} \equiv 1+\frac{\alpha \delta}{1-\delta}+\mu W l$.

Combining with Eq. (17) reveals how labor demand changes. Using $\hat{e}=\hat{L}$, and solving for the employment rate yields the condition for labor market equilibrium $e(\tau ; b, \lambda)$,

$\hat{e}=\frac{1}{\nabla} \frac{W L_{\lambda}}{w L_{W}} \cdot \hat{\lambda}-\frac{1}{\nabla} \cdot(\hat{\tau}+\hat{b}), \quad \nabla \equiv \frac{W}{w L_{W}}+\frac{\eta}{1-\eta} \psi_{e}$

To sum up, net taxes or benefits get partly shifted to employers, inflate costs and reduce labor demand of integrated firms. Since higher wages make integration less profitable, more firms shift to outsourcing. Unemployment among unskilled workers increases. A lower transport cost makes outsourcing more profitable and reduces national labor demand. Again, unemployment rises.

\subsection{Fiscal budget balance}

Redistribution implies a higher tax on high-skilled households, combined with a lower net $\operatorname{tax} \tau$ on the unskilled. Insurance calls for higher unemployment benefits, combined with a higher net tax on the employed unskilled workers. In both cases, the tax $\tau$ on earnings of unskilled workers is endogenously set to balance the fiscal budget. Loglinearizing the budget constraint in Eq. (14) shows to which extent the net tax on the low-skilled must be adjusted. By Eq. (1), a higher tax rate $T$ discourages hours worked of the skilled, $\hat{H}=-\sigma \cdot \hat{T}$, where $\sigma \equiv \varphi^{\prime}$ / $\left(H \varphi^{\prime \prime}\right)>$ is the wage elasticity of labor supply. As usual, the change in the tax rate is expressed relative to the tax factor, $\hat{T} \equiv \mathrm{d} T /(1-T)$. Using $\hat{b} \equiv(\mathrm{d} b) / w$ and $\hat{\tau} \equiv(\mathrm{d} \tau) / w$ yields the budget in log-linearized form,

$\hat{\tau}=\frac{1-e}{e} \cdot \hat{b}-\left[1-\frac{T}{1-T} \sigma\right] \frac{Y_{H}}{e w} \cdot \hat{T}-\tau^{*} \cdot \hat{e}$,

where $Y_{H} \equiv(1-T) r H N$ denotes aggregate net wage income of the high-skilled. For a given employment rate, higher benefits require higher contributions. In contrast, a higher tax on skilled workers allows to cut net taxes of unskilled workers. ${ }^{11}$ Increased employment creates a double fiscal gain proportional to the participation tax rate $\tau^{*}$ as more people switch from joblessness into employment.

\subsubsection{Policy effects}

The equilibrium tax rate and market tightness must simultaneously satisfy labor market clearing and fiscal budget balance. Solving Eqs. (23) and (24) yields

$e w \cdot \hat{e}=\sigma_{E T} \cdot Y_{H} \hat{T}-\sigma_{E B} \cdot w \hat{b}+\sigma_{E \lambda} \cdot e w \hat{\lambda}$,

$e w \cdot \hat{\tau}=-\sigma_{E T} \nabla \cdot Y_{H} \hat{T}+\left(1-e+\sigma_{E B} \tau^{*}\right) \cdot w \hat{b}-\sigma_{E \lambda} \tau^{*} \cdot e W \hat{\lambda}$,

where, for later use, the coefficients are defined as

$\sigma_{E B} \equiv \frac{1}{\nabla-\tau^{*}}>0, \quad \sigma_{E T} \equiv\left[1-\frac{T}{1-T} \sigma\right] \sigma_{E B}, \quad \sigma_{E \lambda} \equiv \frac{L_{\lambda}}{L_{W}} \sigma_{E B}$.

\footnotetext{
11 At very high tax rates, revenue might decline as $1-\frac{T}{1-T} \sigma$ becomes negative (Laffer curve effect). However, it would never be an optimal policy to raise the tax rate to a level where this could occur.
} 
The determinant, $\nabla-\tau^{*}=1 / \sigma_{E B}>0$, must be positive to assure stability. Given stability, raising the tax rate on high wage earners allows to cut the net tax burden of unskilled households, while more spending on insurance requires to raise the tax.

The immediate effect of lower transport costs is an increase in profits $\pi^{o}$, leading more firms to switch to outsourcing which erodes labor demand. For given employment, domestic wages and labor costs are not immediately affected. However, to eliminate excess labor supply, market tightness must fall, leading to lower employment. More people claim benefits and fewer pay contributions. Consequently, the tax $\tau$ on employed workers must be raised to balance the budget (given that $T$ does not change). Globalization not only raises unemployment among the low-skilled but also reduces their wages. ${ }^{12}$ In contrast, per capita profit income increases for two reasons. First, cheaper low-tech imports directly boost profits. Second, since more firms switch to outsourcing, the reduction in labor demand depresses wages, thereby strengthening profits of integrated firms. By Eq. (25) in combination with Eqs. (A.6) and (A.7), the average per capita profit over all firms rises, and high-skilled capital owners gain. Globalization thus creates more inequality.

To fight increasing inequality, governments can redistribute by raising taxes on high-wage earners to finance a tax cut for low-income households. A lower tax helps to reduce unemployment among the low-skilled. The policy acts like a wage subsidy, allowing for higher net wages and lower gross wages, see (Eqs. (A.5)-(A.6)). A lower wage bill boosts job creation and employment. It also boosts profits of integrated firms and thereby reduces the tendency towards outsourcing. This result points to the usefulness of policies to strengthen participation of the low-skilled in a globalized economy. Finally, although the skilled lose on account of a higher tax on labor income, they gain in terms of profits.

A central function of the welfare state is social insurance when private risk markets are missing. Our last experiment raises UI benefits and finances them with higher contributions which add to the overall tax burden $\tau$ of the employed low-skilled. This way, the government allows risk averse workers to shift income from the good to the bad state, creating gains from insurance. Higher benefits boost workers' reservation wages. The policy thereby discourages job creation and raises unemployment. In adding to firms' wage costs, the welfare state reduces profits of integrated firms and induces more outsourcing, further raising unemployment. Via reduced profits, the high-skilled bear part of the burden.

\section{Welfare and optimality}

How do globalization and public policy affect individual welfare in the presence of labor market distortions and missing insurance markets?

\subsection{Efficiency and redistribution}

Skilled workers gain from higher profits but lose when labor taxes rise. Applying the envelope theorem to Eq. (1) yields $N \mathrm{~d} V_{H}=u_{H}^{\prime}$. $\left(-Y_{H} \hat{T}+\mathrm{d} \Pi\right)$. Define $\hat{V}_{H} \equiv \mathrm{d} V_{H} / u_{H}^{\prime}$ and divide by marginal utilities to express welfare changes in money equivalent units. Add the profit change in Eq. (A.7) and substitute the change in unit labor cost,

$N \hat{V}_{H}=-Y_{H} \hat{T}-e w \hat{w}-\frac{\eta}{1-\eta} \frac{\kappa e}{m} \hat{e}-s^{o} \lambda w^{s} l^{s} \hat{\lambda}$.

\footnotetext{
12 The effect is not entirely unambiguous since the necessary tax increase points in the opposite direction of a higher wage. We give a sufficient condition assuring that the direct effect dominates over the induced tax effect. The condition by the way would also guarantee stability, see Eqs. (A.4) and (A.6).
}

Better access of industrialized countries to cheap labor in the South by means of lower transport costs $\hat{\lambda}<0$ boosts profits.

Welfare of unskilled workers changes by $\mathrm{d} V_{L}=u_{E}^{\prime} \cdot e w(\hat{w}-\hat{\tau})+u_{B}^{\prime}$. $(1-e) w b+\left(u_{E}-u_{B}\right) e \hat{e}$, where lower indices $E$ and $B$ refer to the states 'Employed' and 'on Benefits'. Write again $\hat{V}_{L} \equiv \mathrm{d} V_{L} / u_{E}^{\prime}$. Substitute $u_{B}^{\prime}$ by the approximation in Eq. (A.1) and $u_{E}-u_{B}$ by the bargaining condition (7), with the job rent replaced by the job creation condition $\left(F_{l}-w\right)$ $m=\kappa$, yielding, in money equivalent units,

$$
\hat{V}_{L}=(1-e) w \hat{b}+\rho \chi(1-e) w \hat{b}+e w(\hat{w}-\hat{\tau})+\frac{\gamma}{1-\gamma} \frac{\kappa e}{m} \hat{e} .
$$

The welfare change of unskilled workers partly reflects taxes and transfers. Replace the endogenous tax by the differential of the fiscal constraint in Eq. (24). Substitute Eq. (26) to compare with the welfare change of skilled households. Collecting terms and using $\left(F_{l}-w\right)=\kappa /$ $m$ as well as $\hat{H}=-\sigma \hat{T}$ leads to

$$
\begin{aligned}
\hat{V} \equiv & N \hat{V}_{H}+\hat{V}_{L}=\frac{T}{1-T} Y_{H} \cdot \hat{H}+e w \Gamma \cdot \hat{e}+\rho \chi(1-e) w \\
& \cdot \hat{b}-s^{o} \lambda w s l s \cdot \hat{\lambda}, \\
\Gamma \equiv & \tau^{*}+(\gamma-\eta) \cdot \frac{\left(F_{l}-w\right) / w}{(1-\eta)(1-\gamma)} .
\end{aligned}
$$

Welfare changes reflect redistribution and efficiency. Redistribution means that the welfare gain of one group is offset by an equal welfare loss of the other, leaving a net change $\hat{V}=0$. The skilled lose if they face a tax increase and if profits decline. A higher tax directly redistributes to the poor. Redistribution also occurs since a tighter labor market raises income and employment of the unskilled but cuts into profits due to increased hiring costs.

Efficiency effects, equal to the aggregate welfare change $\hat{V}$ in Eq. (28), result from policy induced distortions and preexisting market failures. A higher marginal tax $T$ creates the standard excess burden from distorting intensive labor supply. Expanding low-skilled employment yields efficiency gains proportional to $\Gamma$. Part of the gain is proportional to the participation tax rate $\tau^{*}$ in the sense of Saez (2002). When an individual switches from unemployment into a job, she pays tax and loses benefits and thus incurs a total loss of $\tau^{*} w \equiv \tau+b$. This loss mirrors the double fiscal gain in terms of higher tax revenue and lower social spending. Participation taxes tend to be high for low-income earners in Europe, see Immervoll et al. (2007). Being proportional to $\tau^{*}$, the excess burden from discouraging low-skilled employment could thus be substantial. The second term in $\Gamma$ relates to search frictions. When their bargaining power exceeds the matching elasticity of job search, $\gamma>\eta$, workers get a too high wage and thus a too high share of the job surplus, causing inefficiently high unemployment. Employment enhancing policies create first order welfare gains. If the search equilibrium were efficient in the sense of Hosios (1990), $\gamma=\eta$, there would also be no marginal gain from more employment.

The next term in Eq. (28) corresponds to gains from insurance. Social insurance is valuable for risk averse workers when markets are incomplete and private UI is not available. The gains are proportional to the unemployment rate times the product of the degree of risk aversion $\rho$ and the degree of income variation $\chi$. This term is known from Baily (1978), Gruber (1997) and Chetty (2006), among others. In these papers, all agents are symmetric so that there can be no welfare gains from redistribution but only from insurance. Our paper extends the analysis to an international context.

The last term in Eq. (28) captures the direct efficiency gains from globalization, reflecting the cost savings from better access to cheap labor in the South. Lower transport costs $\lambda$ reduce costs of firms outsourcing to low-wage economies. The net effect on welfare is $\hat{V}=e w \Gamma \hat{e}-s^{o} \lambda w^{s} l^{s} \hat{\lambda}$. It would be clearly positive if the welfare state were absent and labor markets were efficient, implying $\Gamma=0$. The domestic employment effect of more outsourcing magnifies the 
welfare gains if the labor market is overly tight, $\gamma<\eta$. In contrast, if unemployment is inefficiently high, $\gamma>\eta$, the net impact tends to be ambiguous. The gains from lower transport costs would have to be set against the efficiency losses from higher unemployment. These efficiency losses are magnified if there is a high participation $\operatorname{tax} \tau^{*}$ due to the existence of a welfare state.

\subsection{Pareto improving policy}

The basic functions of the welfare state are redistribution and social insurance. To analyze policy, we need the final welfare effects in general equilibrium. Policy changes welfare of skilled households as in Eq. (26) . Appendix A4 derives

$N \hat{V}_{H}=-I_{T} \cdot Y_{H} \hat{T}-I_{B} \cdot w \hat{b}-\left(I_{\lambda} \cdot e W+s^{o} \lambda w^{s} l^{s}\right) \cdot \hat{\lambda}$,

where $I_{B}$ and $I_{T}$ are positive coefficients given in Eq. (A.8) which capture redistributive effects. Substituting Eq. (25) and $\hat{H}=-\sigma \hat{T}$ into Eq. (28) yields the aggregate welfare effect,

$$
\begin{aligned}
\hat{V}=N \hat{V}_{H}+\hat{V}_{L}= & -\left(\frac{T}{1-T} \sigma-\sigma_{E T} \Gamma\right) \cdot Y_{H} \hat{T} \\
& +\left(\rho \chi(1-e)-\sigma_{E B} \Gamma\right) \cdot w \hat{b}-\left(s^{0} \lambda w^{s} l^{s}-\Gamma \sigma_{E \lambda} \cdot e W\right) \cdot \hat{\lambda} .
\end{aligned}
$$

Lower transport costs facilitate outsourcing of unskilled tasks. This trend benefits skilled and harms unskilled workers. Noting $\hat{V}_{L}=\hat{V}-\hat{V}_{H}$, the results in Eqs. (29) and (30) give

$\hat{V}_{H}=-\left(I_{\lambda} e W+s^{o} \lambda w^{s} l^{s}\right) \cdot \hat{\lambda}>0, \quad \hat{V}_{L}=\left(I_{\lambda} e W+\Gamma \sigma_{E \lambda} e W\right) \cdot \hat{\lambda}<0$.

Assuming labor market efficiency and starting from an untaxed equilibrium, globalization $(\hat{\lambda}<0)$ yields efficiency gains of $\hat{V}=-s^{o} \lambda w^{s} l \hat{\lambda}$. The gains from trade are reduced if a high participation tax and excessive unemployment $(\gamma>\eta)$ result in a high distortion $\Gamma$. Given aggregate gains but an uneven distribution as in Eq. (31), is it possible to design a Pareto improving welfare policy? We suggest: (i) keep benefits constant to protect income of the unemployed; and (ii) implement a redistribution policy $\hat{T}>0>\hat{\tau}$ at a scale that prevents rising unemployment and falling disposable income of the unskilled. The tax cut (or wage subsidy) reduces the participation tax and offsets the negative employment effects of globalization. By Eq. (A.5), the change in disposable income is proportional to the employment effect, i.e. $\hat{e}=0$ implies $\hat{w}-\hat{\tau}=0$. If neither incomes $w-\tau$ and $b$ nor employment $e$ change, welfare of the unskilled remains constant. From Eq. (25), we find a redistribution such that employment remains constant,

$\hat{b}=0, \quad Y_{H} \hat{T}=-\frac{L_{\lambda} / L_{W}}{1-\frac{T}{1-T} \sigma} e W \cdot \hat{\lambda} \Rightarrow \hat{V}_{L}=0$.

In fully compensating unskilled workers, this redistribution policy is Pareto improving if it allows skilled households to keep part of the efficiency gain. Noting the cost shares $\frac{s x}{s^{0} x^{0}}=\frac{e W}{s^{\circ} \lambda W^{\sigma}\left[\left.\right|^{5}\right.}$, and substituting Eq. (32) into Eq. (30) yields ${ }^{13}$

$\hat{V}_{H}=\hat{V}=-\left[1-\frac{\frac{T}{1-T} \sigma}{1-\frac{T}{1-T} \sigma} \cdot \frac{L_{\lambda}}{L_{W}} \frac{s x}{S^{0} \chi^{0}}\right] s^{o} \lambda w^{S} l^{s} \cdot \hat{\lambda}$.

\footnotetext{
${ }^{13}$ The technology in Eq. (4) implies $x / x^{o}=\left(\omega^{o} / \omega\right)^{1 / \delta-1}$. The cost advantage from outsourcing makes these firms larger, $x<x^{o}$. With constant cost shares, labor demand coefficients in Eq. (22) are $L_{\lambda} \equiv \mu \alpha \delta x^{o}$ and $L_{W} \equiv 1+\frac{\alpha \delta}{1-\delta}+\mu \alpha \delta x$. Using $\pi^{j}=(1-\delta) x^{j}$ and $\mu \equiv \frac{q g(q)}{s(q)} \frac{q}{\pi^{0}-\pi}$, we have $L_{W}-L_{\lambda}=1+(1-q \cdot q g / s) \frac{\alpha \delta}{1-\delta}>1$, since $q g(q)<s(q)$, so that $\frac{L_{\lambda}}{L_{W}}<\frac{L_{\lambda}}{1+L_{\lambda}}<1$. The larger is the importance of outsourcing $\left(s^{o} x^{o}>s x\right)$, the more likely a reduction in transport cost raises aggregate welfare.
}

When insurance is not cross-subsidized by the skilled $(T=0)$, the redistribution policy allows all groups to share in the gains from trade and makes globalization Pareto improving. By continuity, choosing a policy slightly larger than in Eq. (32) boosts welfare of the unskilled by reducing the unemployment rate and raising disposable income of employed workers. If, however, the government is already redistributing substantially before globalization sets in, a high tax rate $T$ on skilled households creates an excess burden which makes redistribution more costly and reduces the chances for a Pareto improvement.

\subsection{Optimal welfare policy}

A social welfare function $\Lambda=N V_{H}+\xi V_{L}$ captures policy objectives where $\xi \geq 1$ reflects the concern for unskilled workers. An optimal redistribution policy requires $\mathrm{d} \Lambda / \mathrm{d} T=u_{H}^{\prime} N \hat{V}_{H} / \mathrm{d} T+\xi u_{E}^{\prime} \hat{V}_{L} / \mathrm{d} T=0$, where $\hat{V}_{L}=\hat{V}-N \hat{V}_{H}$. Substituting Eqs. (29) and (30) yields

$$
\frac{\xi u_{E}^{\prime}-u_{H}^{\prime}}{\xi u_{E}^{\prime}} \cdot I_{T}=\frac{T}{1-T} \cdot \sigma-\Gamma \cdot \sigma_{E, T}
$$

The left-hand side reflects the gains from distribution when an amount $I_{T}$ is redistributed from the rich with low marginal utility to unskilled workers with high marginal utility of income. The right-hand side expresses the excess burden. The difference to the standard tax literature is low-skilled unemployment and the contrast between intensive and extensive labor supply. Raising $T$ creates an excess burden $\frac{T}{1-T} \cdot \sigma$ due to intensive supply decisions of the skilled. In using revenue to cut the $\operatorname{tax} \tau$ of unskilled workers, or even pay a wage subsidy to them, the government boosts net of tax wages $w-\tau$. The policy also lowers gross wages $w$ which induces job creation and employment. It thus reduces the excess burden from the employment distortion of unskilled workers by $\sigma_{E, T} \Gamma$, as measured by the participation tax rate $\tau^{*}$ which is part of $\Gamma$.

The condition for optimal insurance follows by the same steps as before,

$(1-e) \chi \cdot \rho+\frac{\xi u_{E}^{\prime}-u_{H}^{\prime}}{\xi u_{E}^{\prime}} \cdot I_{B}=\Gamma \cdot \sigma_{E, B}$

To provide insurance to risk averse workers, the government raises taxes (contributions) to pay higher benefits, thereby shifting income from the good to the bad state. The first term reflects the gains from insurance when private UI markets are missing. In addition, the distributive term $I_{B}$ raises welfare of low-skilled workers at the expense of high-skilled workers since UI benefits lead to higher wages and lower profits. The excess burden on the right-hand side reflects the participation tax $\tau^{*}$ that arises when agents switch from employment into joblessness. Starting from small values, the excess burden is zero (in the absence of search distortions when $\eta=\gamma$ ) while the welfare gains from insurance and redistribution are strictly positive to the first order. Eventually, however, the progressively increasing excess burden limits the optimal size of the insurance program.

How do lower transport costs, leading to more outsourcing, affect optimal welfare policies? By Eq. (25), this shock reduces the employment rate and exposes unskilled workers to a larger income risk. By Eq. (31), it also contributes to more inequality, $\hat{V}_{H}>0>\hat{V}_{L}$. The trend to outsourcing thus emphasizes the need for social insurance and redistribution. We conclude that the optimal response to globalization is to expand the role of the welfare state. Since redistributive taxation favors the employed unskilled population, it reduces the participation $\operatorname{tax} \tau^{*}$ and actually makes social insurance less damaging.

\section{Conclusions}

The trend to outsourcing of labor intensive components puts pressure on the welfare states of advanced economies. Based on a model of outsourcing and involuntary unemployment, we have shown how 
integration, by lowering transport costs of intermediate imports, facilitates outsourcing and impairs employment prospects and wages of unskilled workers while at the same time raising profits of top income earners. The resulting inequality and the increased income risk of unskilled workers seemingly emphasize the basic functions of the welfare state, redistribution and social insurance.

The need for an extended welfare state in the presence of globalization pressure arises even if the welfare state itself creates part of the problem that it is designed to solve. Offering higher replacement incomes for more insurance boosts wages and causes higher unemployment. By inducing even more outsourcing than would otherwise obtain, the impact of social insurance on unemployment of low-skilled workers is reinforced. These detrimental effects show up as part of the efficiency costs arising from welfare policies. However, expanding a linear income tax to redistribute more heavily from skilled to unskilled households might involve a smaller efficiency cost than is commonly perceived. Since the income tax redistributes only to households earning an active wage income, it cuts the high participation tax on unskilled workers and widens the income gap between work and joblessness. It thereby acts as a wage subsidy which is often deemed to become more important in advanced welfare states when the integration of the world economy accelerates. In our model, the redistribution in favor of low-skilled workers raises net wages while, at the same time, gross wages fall. It thereby initiates job creation and reduces unemployment among lowskilled workers. Since lower wage costs add to profits of integrated firms, the policy also helps to stem the tide towards outsourcing.

\section{Appendix A}

\section{A.1. Wage bargaining}

The wage impact follows from bargaining, see Eq. (7). Approximate marginal utility by a Taylor expansion. Use $u_{E}^{\prime}=u^{\prime}(w-\tau)$ and $u_{B}^{\prime}=$ $u^{\prime}(b+z)$ as a short-hand where lower indices $E$ and $B$ refer to the states of 'Employment' and 'on Benefits'. Using $\rho \equiv-c u^{\prime \prime} / u^{\prime}$ as well yields

$u_{B}^{\prime} \approx u_{E}^{\prime}+u_{E}^{\prime \prime} \cdot(b+z-w+\tau)=u_{E}^{\prime} \cdot(1+\rho \chi), \quad \chi \equiv \frac{w-\tau-b-z}{w-\tau}$.

Given $u_{E}-u_{B} \approx u_{E}^{\prime} \cdot(w-\tau-b-z)$, we find $d^{u_{E}-u_{B}} \frac{u_{E}^{\prime}}{u_{E}}=(1+\rho \chi)$ $(d w-d \tau-d b)$. Substitute job creation $F_{l}-w=\kappa / m$ into Eq. (7) and use $\eta \equiv-\theta m^{\prime} / m$ and the approximations above. Expressing the change in taxes and benefits relative to the wage yields $(1+\rho \chi) w[\hat{w}-\hat{\tau}-\hat{b}]=\frac{\gamma}{1-\gamma} \frac{\kappa}{m} \eta \hat{\theta}$. Substituting again the bargaining condition on the right hand side and using $u_{E}-u_{B} \approx u_{E}^{\prime} \cdot(w-\tau-b-z)$ and $\hat{e}=(1-\eta) \hat{\theta}$ yields Eq. (16).

\section{A.2. Wages and labor costs}

Further analysis requires the general equilibrium impact on wages. Compare, separately for each shock, the coefficients in Eq. (25) to relate the equilibrium tax rate to the employment rate,

$T: \hat{\tau}=-\nabla \cdot \hat{e}, \quad b: \hat{\tau}=-\left[\tau^{*}+(1-e) / \sigma_{E B}\right] \cdot \hat{e}, \quad \lambda: \hat{\tau}=-\tau^{*} \cdot \hat{e}$.

Consider the wage impact, $\hat{w}=\hat{\tau}+\hat{b}+\frac{1-\tau^{*}-z / w}{1+\rho \chi} \frac{\eta}{1-\eta} \hat{e}$, and use Eq. (A.2). Also use $\hat{b}=-\left(e / \sigma_{E B}\right) \hat{e}$ when evaluating the effect of UI benefits. Noting $\nabla \equiv \frac{w}{w L_{w}}+\frac{\eta}{1-\eta} \psi_{e}$ and $\psi_{e} \equiv \frac{1-\tau^{*}-z / w}{1+\rho \chi}+\frac{\kappa / m}{w}$, the equilibrium relation between wages and employment is

$T: \hat{w}=-\left[\frac{W}{w L_{W}}+\frac{\eta}{1-\eta} \frac{\kappa / m}{w}\right] \cdot \hat{e}$,
$b: \hat{w}=-\left[\frac{W}{w L_{W}}+\frac{\eta}{1-\eta} \frac{\kappa / m}{w}\right] \cdot \hat{e}$,
$\lambda: \hat{w}=\left[\frac{1-\tau^{*}-z / w}{1+\rho \chi} \frac{\eta}{1-\eta}-\tau^{*}\right] \cdot \hat{e}$.
Higher transport costs boost employment which is expected to raise wages in Eq. (A.3). The opposite case is, in principle, possible since higher employment reduces benefit spending and raises tax revenue so that $\tau$ can be cut which tends to allow for a lower wage. This would be a rather pathological case that should be excluded on empirical grounds. Assuming $\eta$ large $(1-\eta$ small $)$ magnifies the direct effect of employment on the wage and makes it more likely to dominate the countervailing effect of the induced tax reduction. The following condition guarantees that a higher transport cost affects employment and wage in the same direction,

$\frac{\eta}{1-\eta}>\frac{(1+\rho \chi) \tau^{*}}{1-\tau^{*}-z / w}$

Obviously, this condition is fulfilled if the government sector is small $\left(\tau^{*} \rightarrow 0\right)$. Henceforth, it is assumed to be fulfilled for positive taxes as well. Evaluating welfare changes requires the change in disposable wage income. Combining Eqs. (A.2) and (A.3) yields

$T: \hat{w}-\hat{\tau}=\frac{1-\tau^{*}-z / w}{1+\rho \chi} \frac{\eta}{1-\eta} \cdot \hat{e}$,

$b: \hat{w}-\hat{\tau}=-\left[\frac{W}{w L_{W}}+\frac{\eta}{1-\eta} \frac{\kappa / m}{w}-\tau^{*}-\frac{1-e}{\sigma_{E B}}\right] \cdot \hat{e}$,

$\lambda: \hat{w}-\hat{\tau}=\frac{1-\tau^{*}-z / w}{1+\rho \chi} \frac{\eta}{1-\eta} \cdot \hat{e}$

Finally, unit labor costs in Eq. (17), $\hat{W}=\frac{w}{W}\left[\psi_{e} \cdot \frac{\eta}{1-\eta} \hat{e}+\hat{\tau}+\hat{b}\right]$, can similarly be related to employment. Using again $\hat{b}=-\left(e / \sigma_{E B}\right) \hat{e}$ and Eq. (A.2) gives

$T: \hat{W}=-\frac{1}{L_{W}} \hat{e}$

$b: \hat{W}=-\frac{1}{L_{W}} \hat{e}$,

$\lambda: \hat{W}=\frac{w}{W}\left[\frac{\eta}{1-\eta} \psi_{e}-\tau^{*}\right] \hat{e}$.

If condition Eq. (A.4) holds, higher transport costs boost wages. The impact on gross wage costs $W$ is positive a fortiori if Eq. (A.4) is satisfied (use $\Psi_{e}$ ). Note that Eq. (A.4) is also sufficient for stability, $\nabla=\frac{W}{w L_{w}}+\frac{\eta}{1-\eta} \psi_{e}>\tau^{*}$.

\section{A.3. Profit income}

Finally, consider profits $\Pi=\bar{\pi} N$. Since $\mathrm{d} s^{o}=-\mathrm{d} s$ and $\mathrm{d} s=-q \mathrm{~d} s^{f}$, profits in Eq. (12) change by $\mathrm{d} \Pi=s \pi \hat{\pi}+s^{0} \pi^{0} \hat{\pi}^{o}+\left[\left(\pi^{o}-\pi\right) q-f^{o}\right] \mathrm{d} s^{f}$. The square bracket is zero by choice of organizational form. Substitute Eqs. (18-19) and note $\pi=(1-\delta) x, l W=\alpha \delta x$ and $e=s l$,

$d \Pi=-e W \cdot \hat{W}-s^{o} l^{s} \lambda w s \cdot \hat{\lambda}$.

Since $\hat{\lambda}>0$ implies $\hat{e}>0$ and by Eq. (A.6) also $\hat{W}>0$, profits unambiguously rise when $\hat{\lambda}<0$ in the wake of globalization.

\section{A.4. Welfare calculations}

To get welfare changes in final form, substitute Eq. (A.3) and Eq. (25) into Eq. (26). Do this separately for $T, b, \lambda$, use Eq. (A.3) in each step, and add up, to get Eq. (29), where coefficients are defined as $I_{T} \equiv 1-\frac{W}{w L_{W}} \sigma_{E T}, \quad I_{B} \equiv \frac{W}{w L_{W}} \sigma_{E B}, \quad I_{\lambda} \equiv\left[\frac{\eta}{1-\eta} \psi_{e}-\tau^{*}\right] \sigma_{E \lambda}$.

Upon substituting terms, the first coefficient becomes

$I_{T}=\left(\frac{\eta}{1-\eta} \psi_{e}-\tau^{*}+\frac{T}{1-T} \sigma \frac{W}{W L_{W}}\right) \sigma_{E B}>0$. 
The assumption Eq. (A.4) used to sign Eq. (A.3) is sufficient for $I_{\lambda}>0$ and, a fortiori, $I_{T}>0$.

\section{References}

Anderton, Bob, Brenton, Paul, 1999. Outsourcing and low-skilled workers in the UK. Bulletin of Economic Research 51, 267-285.

Antràs, Pol, 2005. Incomplete contracts and the product cycle. American Economic Review 95, 1054-1073.

Antràs, Pol, Helpman, Elhanan, 2004. Global sourcing. Journal of Political Economy 112, 552-580.

Baily, Martin N., 1978. Some aspects of optimal unemployment insurance. Journal of Public Economics 10, 379-402.

Blanchard, Olivier J., Tirole, Jean, 2008. The joint design of unemployment insurance and employment protection: a first pass. Journal of the European Economic Association 6, 45-77.

Blundell, Richard, 2006. Earned income tax credit policies: impact and optimality. Labor Economics 13, 423-443.

Burniaux, Jean-Marc, Dang, Thai-Thanh, Fore, Douglas, Förster, Michael, d'Ercole, Marco Mira, Oxley, Howard, 1998. Income Distribution and Poverty in Selected OECD Countries, OECD Economics Department WP No. 189.

Chetty, Raj, 2006. A general formula for the optimal level of social insurance. Journal of Public Economics 90, 1879-1901.

Davidson, Carl, Matusz, Steven J., 2006. Trade liberalization and compensation. International Economic Review 47, 723-747.

Davidson, Carl, Martin, Lawrence, Matusz, Steven J., 1999. Trade and search generated unemployment. Journal of International Economics 48, 271-299.

Davidson, Carl, Matusz, Steven J., Shevchenko, Andrei, 2008. Globalization and firm level adjustment with imperfect labor markets. Journal of International Economics 75, 295-309.

Díaz-Mora, Carmen, 2008. What factors determine the outsourcing intensity? A dynamic panel data approach for manufacturing industries. Applied Economics 40, 2509-2521.

Díaz-Mora, Carmen, Triguero-Cano, Angela, 2007. Why Do Some Firms Contract out Production? Evidence from Firm-Level Panel Data, FEDEA WP 232.

Eckstein, Zvi, van den Berg, Gerard J., 2007. Empirical labor search: a survey. Journal of Econometrics 136, 531-564.

Egger, Hartmut, Egger, Peter, 2003. Outsourcing and skill-specific employment in a small economy: Austria after the fall of the iron curtain. Oxford Economic Papers 55, $625-643$.

Egger, Hartmut, Kreickemeier, Udo, 2008. International fragmentation: boon or bane for domestic employment? European Economic Review 52, 116-132.

Egger, Hartmut, Kreickemeier, Udo 2009. Firm Heterogeneity and the Labour Market Effects of Trade Liberalization, International Economic Review 50, 187-216.

Eissa, Nada, Hoynes, Hilary W., 2006. In: Poterba, J. (Ed.), Behavioral Responses to Taxes: Lessons from the EITC and Labor Supply. Tax Policy and the Economy, vol. 20. MIT Press.

Ekholm, Karolina, Hakkala, Katariina, 2006. The Effect of Offshoring on Labor Demand: Evidence from Sweden, CEPR DP 5648.
Falk, Martin, Wolfmayr, Yvonne, 2008. Services and materials outsourcing to low-wage countries and employment: empirical evidence from EU countries. Structural Change and Economic Dynamics 19, 38-52.

Feenstra, Robert C., Hanson, Gordon H., 1996. Globalization, outsourcing, and wage inequality. American Economic Review 86, 240-245.

Feldstein, Martin, Poterba, James, 1984. Unemployment insurance and reservation wages. Journal of Public Economics 23, 141-167.

Fishe, Raymond P.H., 1982. Unemployment insurance and the reservation wage of the unemployed. Review of Economics and Statistics 64, 12-17.

Grossman, Gene, Helpman, Elhanan, 2002. Integration versus outsourcing in industry equilibrium. Quarterly Journal of Economics 117, 85-120.

Gruber, Jonathan, 1997. The consumption smoothing benefits of unemployment insurance. American Economic Review 87, 192-205.

Guesnerie, Roger, 2001. Second-best redistributive policies: the case of international trade. Journal of Public Economic Theory 3, 15-25.

Helpman, Elhanan, 2006. Trade, FDI, and the organization of firms. Journal of Economic Literature 44, 589-630.

Hijzen, Alexander, Görg, Holger, Hine, Robert C., 2005. International outsourcing and the skill structure of labour demand in the United Kingdom. Economic Journal 115 $860-878$.

Hosios, Arthur, 1990. On the efficiency of matching and related models of search and unemployment. Review of Economic Studies 57, 279-298.

Immervoll, Herwig, Kleven, Henrik J., Kreiner, Claus T., Saez, Emmanuel, 2007. Welfare reform in European countries: a microsimulation analysis. Economic Journal 117,1-44

Keuschnigg, Christian, 2008. Exports, foreign direct investment and the costs of corporate taxation. International Tax and Public Finance 15, 460-477.

Krueger, Alan B., Meyer, Bruce D., 2002. In: Auerbach, A.J., Feldstein, M. (Eds.), Labor Supply Effects of Social Insurance. Handbook of Public Economics, vol. 4. NorthHolland, Amsterdam.

Lancaster, Tony, Chesher, Andrew, 1983. An econometric analysis of reservation wages. Econometrica 51, 1661-1676.

Lucas, Robert E., 1978. On the size distribution of business firms. Bell Journal of Economics 9, 508-523.

Melitz, Marc J., 2003. The impact of trade on intra-industry reallocations and aggregate industry productivity. Econometrica 71, 1695-1725.

OECD, 2004. Benefits and Wages: OECD Indicators. OECD, Paris.

OECD, 2007a. OECD Employment Outlook. OECD, Paris.

OECD, 2007b. Offshoring and Employment: Trends and Impacts. OECD, Paris.

Rodrik, Dani, 1998. Why do more open economies have bigger governments? Journal of Political Economy 106, 997-1032.

Saez, Emmanuel, 2002. Optimal income transfer programs: intensive versus extensive labor supply responses. Quarterly Journal of Economics 117, 1039-1073.

Spector, David, 2001. Is it possible to redistribute the gains from trade using income taxation? Journal of International Economics 55, 441-460.

Strauss-Kahn, Vanessa, 2003. The Role of Globalization in the Within-Industry Shift away from Unskilled Workers in France, NBER WP 9716.

Van den Berg, Gerard J., 1990. Search behaviour, transitions to non-participation and the duration of unemployment. Economic Journal 100, 842-865.

Wolff, Edward N., 1998. Recent trends in the size distribution of household wealth Journal of Economic Perspectives 12,131-150. 